\title{
Attention, Intention, and Priority in the Parietal Lobe
}

\author{
James W. Bisley ${ }^{1}$ and Michael E. Goldberg ${ }^{2}$ \\ James W. Bisley: jbisley@mednet.ucla.edu; Michael E. Goldberg: meg2008@columbia.edu \\ ${ }^{1}$ Department of Neurobiology and Jules Stein Eye Institute, David Geffen School of Medicine, and \\ Department of Psychology and the Brain Research Institute, University of California, Los Angeles, \\ California 90095
}

${ }^{2}$ Mahoney Center for Brain and Behavior and Departments of Neurology and Psychiatry, Columbia University College of Physicians and Surgeons and the New York State Psychiatric Institute, New York, NY 10032

\begin{abstract}
For many years there has been a debate about the role of the parietal lobe in the generation of behavior. Does it generate movement plans (intention) or choose objects in the environment for further processing? To answer this, we focus on the lateral intraparietal area (LIP), an area that has been shown to play independent roles in target selection for saccades and the generation of visual attention. Based on results from a variety of tasks, we propose that LIP acts as a priority map in which objects are represented by activity proportional to their behavioral priority. We present evidence to show that the priority map combines bottom-up inputs like a rapid visual response with an array of top-down signals like a saccade plan. The spatial location representing the peak of the map is used by the oculomotor system to target saccades and by the visual system to guide visual attention.
\end{abstract}

\section{Keywords}

lateral intraparietal area; LIP; saccade; visual search; salience; vision

\section{INTRODUCTION}

\begin{abstract}
Much of modern thinking about attention stems from William James' classic description, "Everyone knows what attention is... the taking possession by the mind, in clear and vivid form, of one out of what seem several simultaneously possible objects or trains of thought. Focalization, concentration, of consciousness are of its essence. It implies withdrawal from some things in order to deal effectively with others" (James 1890). James went on to describe two different varieties of attention: "Passive, reflex, nonvoluntary, effortless; Active and voluntary," a classification that modern jargon has named "bottom-up" and "topdown", respectively. James also pointed out the linkage between attention and orienting: "When we look or listen we accommodate our eyes and ears involuntarily, and we turn our head and body as well." The parietal lobe of the human and nonhuman primate brain has long been associated with attention as well as sophisticated motor planning on the basis of clinical and physiological evidence (Critchley 1953): Patients with parietal lesions exhibit
\end{abstract}

Copyright (@) 2010 by Annual Reviews. All rights reserved DISCLOSURE STATEMENT

The authors are not aware of any affiliations, memberships, funding, financial holdings, or any other conflicts of interests that might be perceived as affecting the objectivity of this review. 
extinction and neglect, deficits of attention; and apraxia, difficulty with planning sophisticated movements.

The human parietal lobe (Figure 1a) was traditionally labeled as an association cortex, appearing to play a role in the processing of sensory information, including perception, decision making, numerical cognition, integration, speech comprehension, and spatial awareness (Critchley 1953). We focus on spatial processing, which combines a number of these processes. While a combination of lesion, predominantly from strokes, functional imaging and electrical stimulation studies have broadened our knowledge of how the parietal lobe functions, the majority of the details have been gained by examining the responses of neurons in monkey parietal cortex.

Within the monkey intraparietal sulcus (Figure $1 b$ ) are a number of areas that integrate information from multiple senses and appear to be important for guiding behavior within specific workspaces. For example, medial intraparietal area (MIP) responses are related to reaching (Johnson et al. 1996), anterior intraparietal area (AIP) responses are related to grasping (Sakata et al. 1995), and lateral intraparietal area (LIP) responses are related to eye movements (Gnadt \& Andersen 1988). However, these overt actions are not the only way that information within these maps is used. To illustrate this we focus on LIP. Originally thought of as a saccade planning area (Gnadt \& Andersen 1988), a debate arose as to whether the responses in LIP are related to visual attention (Colby \& Goldberg 1999) or to the intention to make saccades (Andersen \& Buneo 2002). We propose that LIP acts as a priority map in which stimuli in the world are represented according to their behavioral priority, incorporating both visual and cognitive inputs. We suggest that the map is then read out by the visual system to guide attention and by the oculomotor system to guide eye movements.

In this chapter, we begin by describing the model upon which we base our hypothesis. We show data that led to this hypothesis and data that suggest how the map is composed and updated. We also discuss how this model of LIP is consistent with the plethora of results that have been collected from LIP under a range of conditions. In doing so, we hope to convince the reader that activity in LIP does not represent visual attention or motor intention per se; rather, it creates a map that the brain uses to guide both of these processes.

\section{THE PRIORITY MAP}

Our hypothesis is that neurons in LIP act as a priority map. This hypothesis is strongly based on the concept of the saliency maps of Koch, Itti, and colleagues (Itti \& Koch 2000, Koch \& Ullman 1985, Walther \& Koch 2006). A saliency map is a theoretical model that guides attention primarily based on bottom-up inputs. The concept is that the original image is filtered through several preattentive feature detection filters, such as orientation, intensity, or color. This creates a map for each feature in which the activity represents the strength of the salience of that feature across the image. These feature maps are then combined to create a map of general salience. Attention is then allocated to the peak of the map, using a winnertake-all method. We have chosen to use the term priority map rather than saliency map because the term salience connotes bottom-up influences, as it does in the Koch and Itti models. Using the term priority map (Bisley et al. 2009, Fecteau \& Munoz 2006, Ipata et al. 2009 , Serences \& Yantis 2006) implies that both bottom-up and top-down influences play a major role in the selection of objects for eye movements and attention.

In this view, LIP represents a map of the visual world in which locations or objects with high behavioral priority are represented by greater activity in LIP, and in which locations or objects with low behavioral priority are represented by lower activity. We propose that on a moment-by-moment basis, attention is allocated based on the topography of activity across 
the map and that, when appropriate, saccades are made to the peak of the map. In the next five sections we illustrate that LIP has all of the characteristics of a priority map: It highlights bottom-up signals; it is strongly biased by top-down inputs; and the activity appears to guide both visual attention and eye movements.

\section{VISUAL INPUT AND SALIENCE}

We usually relegate stimuli that are not of interest to the background of a scene and, as such, we would expect them to not stand out on a priority map. For example, when we enter a room we often do not notice stable, uninteresting objects in the environment unless they are brought to our attention. Gottlieb and colleagues (Gottlieb et al. 1998, Kusunoki et al. 2000) showed that this observation is true for neuronal responses in LIP. In this study, an array of eight objects remained on the screen for large periods of time and the animals were rewarded for fixating a small point, rather than to anything related to the stable array of stimuli per se. When the monkeys made a saccade to the fixation point, they brought one or more of the stable, task-irrelevant stimuli into the receptive field of the neuron. A typical LIP neuron responded briskly when a stimulus flashed in its receptive field (Figure $2 b$ ); the abrupt onset of a visual stimulus is a salient event. When a saccade brought a stable stimulus, which had not been made salient, into the receptive field the neuron responded much less (Figure $2 c$ ). However, when the monkey made a saccade that brought a recently flashed stimulus into the receptive field, the cell responded as briskly as it did to the abrupt onset of the stimulus in its receptive field (Figure $2 d$ ). Thus, the so-called visual response of parietal neurons (Robinson et al. 1978, Yin \& Mountcastle 1977) reports not the arrival of photons in the receptive field, but rather the salience of the objects emitting those photons. The vast majority of LIP neurons recorded behaved in this way, suggesting that when a stimulus is part of the background, it is represented by low activity in LIP.

Stimuli that are inherently salient are represented in LIP by greater responses. This was best demonstrated by Balan \& Gottlieb (2006) who had a monkey perform a search task in which one of a number of placeholders morphed into the search target. Although the array was stable, before the search target appeared they introduced a perturbation to a member of the array (Balan \& Gottlieb 2006). Five forms of perturbation all induced an increased response: an increase in luminance, a decrease in luminance, an equiluminant change in color, the onset of a frame, and a back-and-forth radial movement (Figure 3). Of note is the fact that moving or flashing (in terms of a change in luminance) perturbations induced greater responses in LIP, consistent with our general experience of having attention captured by transients in the visual world (Yantis \& Jonides 1984).

\section{THE PRIORITY MAP INCORPORATES TOP-DOWN FEEDBACK}

One of the important features of a priority map is the incorporation of top-down feedback. It has been suggested that earlier visual areas, such as V1 (Li 2002) and V4 (Mazer \& Gallant 2003), may act as salience maps, but to be a true priority map, top-down information needs to have a strong influence on the bottom-up visual information. In LIP, top-down information has been shown both to enhance and to suppress activity.

Experimentally, enhanced activity in LIP is often driven by task demands. Thus, when a monkey makes a saccade bringing a task-irrelevant stable object into the receptive field of a neuron the response is usually weak (Figure 2c), but if the monkey knows that the object will be the target of the next saccade, this top-down consideration results in a robust postsaccadic response (Figure 4) (Gottlieb et al. 1998, Kusunoki et al. 2000). Similarly, the response of LIP neurons to perturbations is modulated by whether the search target will appear at or away from the perturbed site (Figure 3, right panel). Variations of top-down biases have been shown in a number of visual search tasks in which a particular target must 
be differentiated from an array of distractors (Buschman \& Miller 2007, Ipata et al. 2006a, Mirpour et al. 2009, Oristaglio et al. 2006, Thomas \& Pare 2007). In each case, the activity in LIP ended up being stronger for the target of the search than for any distractor.

A large component of this top-down influence may be related to the relationship between the stimulus in the receptive field and the likelihood that it will provide the animal with a reward. In the example in Figure 4, the top-down enhancement could be due to the highlighting of a stimulus as a target, but it could also be due to the increase in behavioral relevance driven by the relationship between the item and the reward now linked with it. A number of studies have examined the responses of LIP neurons in terms of their rewardrelated properties, and it is clear that part of the top-down influence is related not just to the absolute value of a reward, but to its relative value (Bendiksby \& Platt 2006, Dorris \& Glimcher 2004, Platt \& Glimcher 1999, Seo et al. 2009, Sugrue et al. 2004). Initially, Platt \& Glimcher (1999) showed that LIP neurons responded more to a stimulus that would provide a bigger reward than to a stimulus that would provide a smaller reward, but more recent studies have suggested that the activity actually represents "expected value" (Sugrue et al. 2004) or "subjective desirability" (Dorris \& Glimcher 2004). In other words, the neural responses to a stimulus are related, in a nuanced way, to the expected outcome of responding to that stimulus. Note that the reward does not have to be in the form of juice; similar modulation is seen when part of the reward is the chance to view social information not normally readily available, such as to stare at a more dominant male's face (Klein et al. 2008). For this review, the key point is that because most experiments on monkeys rely on rewards related to eye movements to collect data, it is almost certain that a large part of the top-down enhancement seen related to "behavioral importance" is related directly to the reward related to that stimulus expected by the animals. However, Maunsell (2004) pointed out that reward evokes attention, and no study has yet addressed the issue of whether a stimulus that predicts an aversive result is as effective a stimulus for LIP as a stimulus that predicts a reward.

Top-down suppression in LIP is less common. The response to a popout distractor in a visual search task is suppressed when an overtrained animal is able to successfully ignore it (Ipata et al. 2006b). By definition, a highly salient stimulus should be represented by high activity on a priority map, so one would expect that a popout stimulus should have elevated activity and attract attention (Balan \& Gottlieb 2006). In this case, monkeys were trained in a free-viewing search task, in which they had to release a bar with either the left or right hand to indicate the orientation of a target. Apart from an initial resetting of the eye to the center of the screen at the beginning of each trial, there were no restrictions on the animals' eye movements. They were not punished if they looked at a distractor and did not have to look at the target to get a reward (Ipata et al. 2009; Ipata et al. 2006a, 2006b). On some trials all of the objects in the array were black; on some trials one stimulus popped out by virtue of being green and brighter than the other array members. The monkeys' performance in this task resembled that of humans: There was a clear set-size effect on reaction time when all members of the array were black, but little if any when the target popped out. Reaction time was even longer when a distractor popped out (Bisley et al. 2009). During the recording experiments, after the psychophysics had been established, the popout stimulus was never the target of the search. Although looking at the popout did not change the probability of the monkey getting a reward (there were no rules governing eye movements), it did delay the getting of the reward, as it increased the number of saccades the monkeys made before fixating the target. As in normal primate behavior, the animals almost always looked at the target before releasing the bar and, presumably to optimize performance, they made a minimal number of eye movements, looking straight to the target soon after the array appeared on about half the trials (Bisley et al. 2009). As such, over a period of many tens of thousands of trials, the monkeys began to ignore the popout stimulus, as measured by a 
reduction in first eye movements made to it. When the neural responses were recorded from LIP, the responses to the popout were usually less than to a distractor (Figures $5 a, b$ ). However, when the mean responses from individual sessions were plotted as a function of how likely the animal was to make its first saccade to the popout within the session, a relationship was seen between the difference in response to the popout and distractor and the salience (i.e., automatic grabbing of attention) of the popout in that session (Figure $5 c$ ). On days in which the animal could not help but look at the popout first on more than 5\% of trials, the mean response to the popout was the same as or greater than the response to a distractor. However, on days in which the animal almost completely ignored the popout (i.e., when the proportion of first saccades went to the popout on less than $2 \%$ of trials), the response to the popout was always lower than to a distractor. These data indicate that the normal high response to a salient feature can be suppressed by training, resulting in a reduced attentional capture by the popout (Ipata et al. 2006b).

Top-down suppression of normally enhanced responses in LIP also provides a way of keeping track of which stimuli have been examined in goal-directed search (Mirpour et al. 2009). As described so far, the priority map sets the scene for guiding visual search; targets are highlighted and distractors are suppressed. But searching for an item is a dynamic process; stimuli are examined and, if the target of the search is not found, the eyes move on. If eye movements are guided by the activity on the priority map, then something must be done to make sure that the eyes will not come back to the previously checked stimulus. In designing their saliency map models, Koch, Itti, and colleagues took a behavioral phenomenon called inhibition of return as their guide (Itti \& Koch 2000, Koch \& Ullman 1985). Inhibition of return is the slowing down of reaction times in response to a stimulus that is placed at a previously attended location (Klein 2000). Described as a mechanism that biases the system to attend to novel locations or items, Koch \& Ullman (1985) implemented this into their model by suppressing the activity representing a stimulus that was being attended. Thus, once attention shifted away from the stimulus, it was no longer strongly represented on the map and would not draw attention back immediately. Such inhibition has been seen in LIP, where responses representing potential targets are reduced after the potential targets have been examined and ruled out as being reward-loaded (Mirpour et al. 2009). This activity can explain why patients with parietal lesions often revisit items they have already examined (Mannan et al. 2005). As in most examples of response modulation in LIP, this can be explained by reward likelihood; a potential target has a particular reward probability. However, once it has been examined and does not give the reward, then its reward probability drops significantly. In this case, the suppression is the result of top-down information based on the guidance of visual search, but it can also be seen as a form of short-term spatial memory; reducing the activity of seen stimuli allows the animal to remember which potential targets he has seen. The responses to the remaining potential targets do not increase as the reward probability increases, which suggests that LIP activity is not a simple, constantly updated representation of reward probability (Mirpour et al. 2009).

\section{CONSTRUCTION OF THE PRIORITY MAP}

Inputs to LIP come from the visual system, the oculomotor system, and a host of other cortical and subcortical areas. Thus far, we have talked about bottom-up and top-down inputs to LIP based on its physiological responses to given stimuli. However, these results are supported by neuroanatomical studies that have shown LIP receiving inputs from both the traditional dorsal and ventral streams of visual processing, including areas V2, V3, V3a, MT, MST, V4, and IT (Baizer et al. 1991, Blatt et al. 1990, Distler et al. 1993, Lewis \& Van Essen 2000). It also receives input from a wide range of other cortical and subcortical areas, 
such as the frontal eye field, anterior cingulate cortex, the claustrum, and a host of thalamic nuclei (Baizer et al. 1993, Blatt et al. 1990).

The various inputs to LIP, as defined physiologically, appear to provide distinctly different components to the activity of neurons in LIP (Ipata et al. 2009). When the monkeys perform the free-viewing search task described above, three different signals are present (Figure 6a) in LIP. For the first 70 or so ms after the appearance of the array the responses to a target or a distractor in the receptive field are identical. This is an undifferentiated, bottom-up visual response, which carries no information about the nature of the object in the receptive field or the direction of the impending saccade (Ipata et al. 2009, Thomas \& Pare 2007). Soon thereafter, however, the responses diverge according to whether or not the monkey will actually make a saccade to the receptive field or elsewhere (Ipata et al. 2006a, Thomas \& Pare 2007). The difference in response, which is dependent upon the direction of the impending saccade, is a top-down "saccadic" signal. However, the response is also modulated by the nature of the object in the receptive field even when the monkey is not going to make a saccade to that object on the next or even the second saccade of the trial. The difference between the response to the target and a distractor is a top-down catch-all described as the "cognitive" signal. The cognitive signal is found also on trials in which the monkey makes a saccade to the receptive field.

Of most interest to this review, Ipata and colleagues showed that if the three signals are broken down from three different trial conditions, they can be summed up to give an almost perfect representation of the fourth trial condition, which incorporates all three signals (Ipata et al. 2009). The logic behind this deconstruction followed by summation is illustrated in Figure $6 \mathrm{a}$. First, the responses containing both a visual and cognitive signal were collected from trials in which the target appeared in the receptive field, but to which the first saccade was not made. Thus, this signal is devoid of the saccadic signal. The authors then subtracted the activity from trials in which only a visual signal was present (i.e., trials in which a distractor that was not the goal of the first saccade was in the receptive field) from the activity from the visual and cognitive trial type. This left the cognitive signal alone. The authors found that a multiplicative factor was needed to amplify the cognitive signal when the saccadic signal was absent. They calculated this factor using mean data from the appropriate animal, but excluding the neuron being examined (Ipata et al. 2009). After multiplying the cognitive signal by this factor, it was added to the activity recorded from trials in which a saccade was made directly to a distractor in the receptive field. This activity represents the visual and saccadic signals. Thus, the resultant signal contained all three components. The authors then compared this response to the response from trials in which all three signals were present, when the first saccade was made towards the target that was in the receptive field. Figure $6 b$ shows the summed and actual responses from a single neuron. To quantify the similarity, the authors compared the responses over 20-ms blocks from 80 to $240 \mathrm{~ms}$ after array onset and plotted a line of best fit. They found that the mean slopes of the lines of best fit from the population of neurons were not significantly different from $45 \mathrm{deg}$ (Figures $6 c, d$ ), suggesting that the summation analysis holds up over single neurons as well as over the population.

\section{THE RELATIONSHIP BETWEEN LIP AND COVERT ATTENTION}

Covert attention is the generation of attention without making a saccade to the attended object. If, as we have claimed, a priority map is used to guide covert attention, then there should be a relationship between the activity in LIP and measures of covert attention. Numerous early studies had claimed to show such a relationship (Bushnell et al. 1981, Lynch et al. 1977, Robinson et al. 1978), yet covert attention was never actually measured. For example, recordings from posterior parietal cortex, of which LIP was a part at the time, 
showed an enhanced response when a stimulus had to be monitored than when it was task irrelevant (Bushnell et al. 1981). This was later explicitly shown in LIP (Colby et al. 1996). However, these studies relied on the assumption that if an animal has to respond to a change in stimulus intensity, then it will attend to that location, and if it does not have to respond to the stimulus, then it will not attend to that location. On first glance, this assumption appears valid; however, it is possible that attention could be grabbed by the task-irrelevant peripheral stimulus. Furthermore, it is also possible that the monkeys did not pin their attention on the peripheral stimulus in the attention task, as a change in luminance itself grabs attention (Yantis \& Jonides 1984) and would allow the animal to perform the task without maintaining peripheral attention at the stimulus location.

To link the activity in LIP and covert attention, Bisley \& Goldberg trained monkeys on a dual task in which they identified the locus of attention by measuring contrast sensitivities (Bisley \& Goldberg 2003, 2006). In this task (Figure 7a), monkeys were trained to plan a memory-guided eye movement to a particular location in space (the saccade goal). While waiting for the instruction to make the saccade, an array of 4 rings flashed for about $17 \mathrm{~ms}$. One of the rings (the probe) had a gap on one side and the monkey had to determine whether the gap was on the left or right. The animal indicated its choice by either canceling the saccade plan (if the gap was on one side) or not canceling it (if the gap was on the other side). By varying the contrast of the four rings, the authors could create contrast functions at each location in which the probe could appear. By definition, a location with enhanced contrast sensitivity is an attended location. On some trials, a task-irrelevant distractor flashed at a location opposite the saccade goal, and this was included to briefly capture attention.

In performing the task, the animals first pinned their attention at the saccade goal. On trials in which the distractor was presented, an attentional benefit in contrast threshold was seen at the distractor location, but not the saccade goal, $200 \mathrm{~ms}$ following the distractor onset (Figure 7b, upper panel). This was inverted $500 \mathrm{~ms}$ later; contrast thresholds were better at the saccade goal than at the distractor location. Thus, the monkey's attention started out at the saccade goal, was briefly captured by the distractor, and then returned to the saccade goal.

The activity and the time course of the activity in LIP were related to the locus of attention. Typically, LIP neurons respond with a visual burst when the target for a memory-guided saccade appears; they then retain an elevated firing rate ("persistent" or "delay" activity) until the saccade is made, at which time they often show a small burst in activity (Barash et al. 1991). The neurons in this task behaved no differently, despite the presentation of a distractor or the array of rings (Figure $7 b$, lower panel).

The two traces in the lower panel of Figure $7 b$ really represent the population responses at two locations on the priority map: the response of the neurons at the location where the target appeared (blue) and the response of the neurons at the location where the distractor flashed (red). The data can be thought of as a sustained peak of activity at the saccade goal along with a transient burst at the distractor location. If these data are compared to the behavioral data, it becomes clear that when the response at the distractor site is higher than the delay activity at the saccade goal, then there was an attentional benefit at the distraction location (the first red triangle in upper panel of Figure $7 b$ is lower than the blue triangle). However, when the response at the saccade goal is higher than the response to the distractor (at $455,700,840$, and $1200 \mathrm{~ms}$ ), an attentional benefit was seen at the saccade goal (the blue points are less than the red point in the upper panel of Figure $7 b$ ). 
To confirm the relationship between the activity in LIP and the attentional benefit, the authors looked at the behavioral performance at three times during the task based on the LIP responses in two animals. At $340 \mathrm{~ms}$, the activity at the distractor site began to drop below the delay response at the saccade goal in this animal. This is indicated by the increase in pvalue on the inverted scale in the lower plot in Figure $7 b$. At $455 \mathrm{~ms}$, the activity at the distractor site began to drop below the delay response at the saccade goal in the second animal, but was already low in this animal. At $840 \mathrm{~ms}$, the activity was clearly greater at the saccade goal in both animals. The prediction was that if attention is allocated to the site of greatest activity, then at the time when the two traces are crossing, there should be no difference in performance at the two locations. This was what the authors found; at $340 \mathrm{~ms}$ there was no attentional advantage in the behavioral data at either the saccade goal or the distractor location. However, in the second monkey, attention was still at the distractor location at $340 \mathrm{~ms}$, consistent with higher activity at the distractor site in that animal. Conversely, at the time the activity was equal in the second monkey (455 ms), no attentional benefit was seen in either location in that animal, but the distractor activity had already dropped in this animal and an attentional benefit was already seen at the saccade goal. The time at which attention shifted from the distractor back to the saccade goal was present at the level of the single neuron (Bisley \& Goldberg 2006, Ganguli et al. 2008), suggesting that this behavioral trait is hardwired into the network properties of the neurons. In any case, this double dissociation suggests that the activity in LIP is related to the allocation of covert attention in a way consistent with a priority map: Attention is allocated to the peak of activity in LIP.

Previous studies of attention in the parietal cortex in general (Bushnell et al. 1981, Robinson et al. 1978) and LIP in specific (Colby et al. 1996) emphasized the enhanced response evoked by the attended object, a tradition that goes back to the early days of attention studies in behaving monkeys (Goldberg \& Wurtz 1972, Moran \& Desimone 1985). The assumption was that the enhanced response to the object in the receptive field correlated with the monkey's attention to it. In the contrast sensitivity experiment, however, the determinant of attention was not the activity evoked by the probe (Bisley \& Goldberg 2003, 2006). On successful trials the response to the GO probe in the receptive field was not different from the response to a ring (null probe) in the receptive field when the successfully perceived probe lay elsewhere (blue and red traces, Figure 8). Instead, the determinant of attention was the peak of the priority map when the probe appeared (time 0 in Figure 8), which had set up a locus of attention that was operating when the probe activity reached the visual area performing the discrimination. The only case in which a probe evoked a greater response was when the monkey was planning a saccade and a NOGO probe appeared within the receptive field. In this case the response to the probe remained high much longer than when the probe confirmed the saccade plan (purple and orange traces, Figure 8). This finding is consistent with the intuitive idea that a stimulus signaling a change in motor output has a higher behavioral priority than one that confirms the status quo and is consistent with results from LIP in a reach-or-saccade task (Snyder et al. 1998).

The effects of reversible lesions in LIP are also consistent with LIP's importance in the generation of attention. Transient inactivation of LIP using muscimol injected into multiple sites in LIP caused monkeys to have longer reaction times to locate a target in search tasks when the target was in the contralateral visual field, but had no effect on reaction times in the ipsilateral visual field (Wardak et al. 2004). 


\section{THE RELATIONSHIP BETWEEN LIP AND THE GENERATION OF SACCADES}

Saccades and attention are ordinarily tightly linked. Most of the time humans and nonhuman primates make saccades to their object of attention. LIP was first identified as a unique area within posterior parietal cortex by virtue of its connections to the oculomotor system (Andersen et al. 1985), suggesting that it played a role in eye movement control (Gnadt \& Andersen 1988). In fact, for many years it was suggested that LIP played a role in motor intention (Mountcastle et al. 1975), which was defined as explicitly planning the next saccade (Mazzoni et al. 1996), or planning the next saccade that may or may not be made (Andersen \& Buneo 2002). This hypothesis was supported by data that showed elevated responses to targets of saccades under a number of conditions. However, unlike the frontal eye field (Bruce et al. 1985, Robinson \& Fuchs 1969) and the intermediate layers of the superior colliculus (Robinson 1972, Schiller \& Stryker 1972) only high current microstimulation of LIP could produce saccades (Constantin et al. 2007, Shibutani et al. 1984, Thier \& Andersen 1998), so although it was implied that LIP activity was related to saccades, no study had shown a direct correlation between eye movements and the activity in LIP.

Further evidence for the intention theory of LIP arose from experiments in which monkeys had simultaneously to plan a reaching movement and a saccade to different targets (Snyder et al. 1997). Delay period activity in LIP was greater when the monkey was planning a saccade to the target than when the monkey planned a reach to it. A reanalysis of the data showed that for the first $300 \mathrm{~ms}$ there was no difference between saccade and reach locations (Quian Quiroga et al. 2006). Although the authors used these data to claim that LIP was more related to saccade intention than to attention, they did not actually measure the locus of the monkey's attention, but rather asserted that the monkey's visual attention lay at both the reach and saccade targets throughout the delay period. In fact, at least in humans, attention as measured by perceptual threshold stays at the saccade goal for the entire delay period, but leaves the reach goal after $300 \mathrm{~ms}$ (Deubel \& Schneider 2003). It is not unreasonable to assume that in the dual task recordings attention left the reach goal at the same time at which the activity in LIP declined. Therefore the decline in activity in LIP during a delayed reach is quite consistent with a priority map interpretation of activity in LIP.

More convincing evidence for the role of LIP in the generation of saccades came from the free-viewing search task described above (Figures 5 and 6). Because the monkeys were not punished for making saccades to a distractor, they made quite short latency saccades (151 and $146 \mathrm{~ms}$ for the two monkeys, respectively) (Ipata et al. 2006a). More surprisingly, activity in LIP correlated with the saccadic reaction time (Figure 9). In an easier search task, in which the monkey only had to find a popout stimulus in an array of eight objects but had to report the results of the search by making a saccade to the popout, saccadic latency was much longer (192 ms), and frontal eye field visuomovement neurons did not predict saccadic reaction time (Thompson et al. 1996), presumably because punishment for making the wrong saccade caused the animals to recheck their saccade plan after the FEF decision to make the saccade.

The antisaccade task, in which a subject has to make a saccade away from a target, has been used to separate stimulus responses from movement responses (Hallett \& Adams 1980). The great bulk of neurons in LIP respond to the stimulus away from which the monkey must move its eyes, some of which subsequently respond to the saccade when its spatial location is in their receptive field (Gottlieb \& Goldberg 1999), even when the same neurons do not 
have a traditional presaccadic response, as tested using a memory-guided delayed saccade task (Zhang \& Barash 2000).

\section{BEYOND ATTENTION AND SACCADES: OTHER FINDINGS IN LIP}

Activity in LIP also reflects the dynamics of a decision process. In tasks in which monkeys must evaluate evidence to determine the direction of an impending saccade, activity in LIP gradually increases in the neurons representing the chosen goal and decreases at the rejected goal (Gold \& Shadlen 2007). The more difficult the decision, the slower the increase of neuronal activity. Whether the activity is a direct measure of the decision process or a representation about how sure that the animal will get a reward for making an eye movement to that stimulus (which is a direct measure of the output of the decision process), the activity in LIP appears to represent the temporal dynamics of the process (Gold \& Shadlen 2007). Thus, activity in LIP has been shown to illustrate the process in estimating time (Janssen \& Shadlen 2005, Leon \& Shadlen 2003, Maimon \& Assad 2006), the direction of motion of a noisy stimulus (Churchland et al. 2008, Roitman \& Shadlen 2002, Shadlen \& Newsome 2001), confidence (Kiani \& Shadlen 2009), and probabilistic reasoning (Yang \& Shadlen 2007).

Not all neurons in LIP may be operating as a priority map; a subset with both spatial and nonspatial encoding properties may play additional roles but do not disrupt the function of the area as a priority map. In a number of studies, activity in LIP neurons has been found to contain nonspatial information, although in almost all cases this is superimposed on spatial responses. In one exception, weak, but significant, categorization activity is found in neurons with receptive fields far removed from the stimulus location (Freedman \& Assad 2009). In another exception, activity across LIP weakly differentiates between instructions to make eye or arm movements before a target is presented (Dickinson et al. 2003). However, in both cases the responses are substantially less than the same responses when a relevant stimulus is presented in the receptive field, so it is not clear whether these weak global responses are being processed in LIP or are a remnant of one of its inputs.

Within the spatial confines of an LIP neuron's receptive field, information pertaining to stimulus shape (Sereno \& Maunsell 1998), direction of motion (Fanini \& Assad 2009), categorization (Freedman \& Assad 2006), color (Toth \& Assad 2002), handedness (Oristaglio et al. 2006), and even numerosity (Roitman et al. 2007) has been found in LIP. Generally, these nonspatial responses have been found in a subset of neurons and a recent study has shown a distinct subset of LIP neurons that are spatially tuned and do not show any obvious nonspatial activity (Ogawa \& Komatsu 2009). Thus, whether or not neurons that also have nonspatial activity contribute to the priority map role of LIP, there is a clear spatial-only response across LIP that is strong enough to act as a priority map. Indeed, inactivation of LIP biases spatial processing, but does not effect the handedness of response (Balan \& Gottlieb 2009) nor the discrimination of shape (Wardak et al. 2004). In addition, LIP inactivation has no effect on the processing of this nonspatial information when the monkey signals an answer by making a saccade to a point outside the receptive fields of the inactivated neurons, suggesting that the relevant activity seen in LIP is indeed just the output of a decision process occurring elsewhere (Balan \& Gottlieb 2009).

\section{ATTENTION, MOTOR INTENTION, DECISION MAKING, AND THE PRIORITY MAP}

The experiments described above led to a welter of frankly confusing results about the role of LIP in the generation of behavior in general and of visual attention and saccadic eye movements. For example, LIP responds more strongly to a stimulus that tells the monkey to 
cancel a saccade plan than it does to a stimulus that confirms the plan. Conversely, under conditions of visual free search, LIP predicts not only the goal but also the latency of visually guided saccades, yet at the same time it describes the nature of the object in the receptive field independently of the direction of the current or next planned saccade. One way to understand these apparently contradictory responses is by a mode switch: Sometimes LIP describes a saccade; sometimes it drives attention; sometimes it accumulates evidence. If this were the case, the brain would somehow have to know how to turn the mode switch, when to use the LIP signal for attention, for saccade planning, and for decision making.

The alternative hypothesis is that LIP provides a priority map that describes the behavioral importance of objects in the visual field. This priority map is built up of a number of disparate top-down and bottom-up signals describing, among others, the abrupt onset of objects in the visual field, saccade planning, value, the nature of the pattern in the visual field, its category, and how close it is to being the chosen object in a decision process. The spikes that contribute to the map lose their identity: Saccade planning spikes are counted no differently than are visual spikes. The oculomotor system drives saccades to the peak of the priority map when saccades are appropriate and the visual system pins attention to the same peak. This makes psychological sense: Attention usually lies at the goal of planned memoryguided saccade unless it is pulled away by the abrupt onset of a salient, task-irrelevant stimulus; and saccades can rapidly be made to the abrupt onset of a visual stimulus (Boch et al. 1984). This hypothesis is consistent with the results from a wide range of studies on LIP and represents the integration of information that acts in far space, the space explored by eye movements. We propose that other maps in the parietal lobe may play similar functions in other workspaces, such as near space (VIP), immediate extrapersonal space (MIP), and hand space (AIP).

Furthermore, because most LIP neurons display perisaccadic remapping (Duhamel et al. 1992, Kusunoki \& Goldberg 2003), the priority map is updated around the time of each saccade. This means that the combined top-down and bottom-up information is always present at the correct retinal location. Thus at any given time, both the oculomotor and visual systems have a spatially appropriate priority map that they can use to guide both visual attention and saccades.

\section{Acknowledgments}

J.W.B. is supported by a Klingenstein Fellowship Award in the Neurosciences, an Alfred P. Sloan Foundation Research Fellowship, a McKnight Scholar Award, and the National Eye Institute (R01 EY019273). M.E.G. is supported by the Zegar, Keck and Dana Foundations and the National Eye Institute (R01 EY014978, R01 EY017039).

\section{LITERATURE CITED}

Andersen RA, Asanuma C, Cowan WM. Callosal and prefrontal associational projecting cell populations in area $7 \mathrm{a}$ of the macaque monkey: a study using retrogradely transported fluorescent dyes. J Comp Neurol. 1985; 232:443-55. [PubMed: 3980763]

Andersen RA, Buneo CA. Intentional maps in posterior parietal cortex. Annu Rev Neurosci. 2002; 25:189-220. [PubMed: 12052908]

Baizer JS, Desimone R, Ungerleider LG. Comparison of subcortical connections of inferior temporal and posterior parietal cortex in monkeys. Visual Neurosci. 1993; 10:59-72.

Baizer JS, Ungerleider LG, Desimone R. Organization of visual inputs to the inferior temporal and posterior parietal cortex in macaques. J Neurosci. 1991; 11:168-90. [PubMed: 1702462]

Balan PF, Gottlieb J. Integration of exogenous input into a dynamic salience map revealed by perturbing attention. J Neurosci. 2006; 26:9239-49. [PubMed: 16957080] 
Balan PF, Gottlieb J. Functional significance of nonspatial information in monkey lateral intraparietal area. J Neurosci. 2009; 29:8166-76. [PubMed: 19553456]

Barash S, Bracewell RM, Fogassi L, Gnadt JW, Andersen RA. Saccade-related activity in the lateral intraparietal area. I. Temporal properties; comparison with area 7a. J Neurophysiol. 1991; 66:1095108. [PubMed: 1753276]

Bendiksby MS, Platt ML. Neural correlates of reward and attention in macaque area LIP. Neuropsychologia. 2006; 44:2411-20. [PubMed: 16757005]

Bisley JW, Goldberg ME. Neuronal activity in the lateral intraparietal area and spatial attention. Science. 2003; 299:81-86. [PubMed: 12511644]

Bisley JW, Goldberg ME. Neural correlates of attention and distractibility in the lateral intraparietal area. J Neurophysiol. 2006; 95:1696-717. [PubMed: 16339000]

Bisley, JW.; Ipata, AE.; Krishna, BS.; Gee, AL.; Goldberg, ME. The lateral intraparietal area: a priority map in posterior parietal cortex. In: Jenkin, M.; Harris, L., editors. Cortical Mechanisms of Vision. Cambridge: Cambridge Univ. Press; 2009. p. 9-34.

Blatt GJ, Andersen RA, Stoner GR. Visual receptive field organization and cortico-cortical connections of the lateral intraparietal area (area LIP) in the macaque. J Comp Neurol. 1990; 299:421-45. [PubMed: 2243159]

Boch R, Fischer B, Ramsperger E. Express-saccades of the monkey: reaction times versus intensity, size, duration and eccentricity of their targets. Exp Brain Res. 1984; 55:223-31. [PubMed: 6745363]

Bruce CJ, Goldberg ME, Bushnell MC, Stanton GB. Primate frontal eye fields. II. Physiological and anatomical correlates of electrically evoked eye movements. J Neurophysiol. 1985; 54:714-34. [PubMed: 4045546]

Buschman TJ, Miller EK. Top-down versus bottom-up control of attention in the prefrontal and posterior parietal cortices. Science. 2007; 315:1860-62. [PubMed: 17395832]

Bushnell MC, Goldberg ME, Robinson DL. Behavioral enhancement of visual responses in monkey cerebral cortex. I Modulation in posterior parietal cortex related to selective visual attention $\mathrm{J}$ Neurophysiol. 1981; 46:755-72.

Churchland AK, Kiani R, Shadlen MN. Decision-making with multiple alternatives. Nat Neurosci. 2008; 11:693-702. [PubMed: 18488024]

Colby CL, Duhamel JR, Goldberg ME. Visual, presaccadic, and cognitive activation of single neurons in monkey lateral intraparietal area. J Neurophysiol. 1996; 76:2841-52. [PubMed: 8930237]

Colby CL, Gattass R, Olson CR, Gross CG. Topographical organization of cortical afferents to extrastriate visual area PO in the macaque: a dual tracer study. J Comp Neurol. 1988; 269:392-413. [PubMed: 2453534]

Colby CL, Goldberg ME. Space and attention in parietal cortex. Annu Rev Neurosci. 1999; 22:31949. [PubMed: 10202542]

Constantin AG, Wang H, Martinez-Trujillo JC, Crawford JD. Frames of reference for gaze saccades evoked during stimulation of lateral intraparietal cortex. J Neurophysiol. 2007; 98:696-709. [PubMed: 17553952]

Critchley, M. The Parietal Lobes. London: Edward Arnold; 1953.

Deubel H, Schneider WX. Delayed saccades, but not delayed manual aiming movements, require visual attention shifts. Ann NY Acad Sci. 2003; 1004:289-96. [PubMed: 14662468]

Dickinson AR, Calton JL, Snyder LH. Nonspatial saccade-specific activation in area LIP of monkey parietal cortex. J Neurophysiol. 2003; 90:2460-64. [PubMed: 12801893]

Distler C, Boussaoud D, Desimone R, Ungerleider LG. Cortical connections of inferior temporal area TEO in macaque monkeys. J Comp Neurol. 1993; 334:125-50. [PubMed: 8408755]

Dorris MC, Glimcher PW. Activity in posterior parietal cortex is correlated with the relative subjective desirability of action. Neuron. 2004; 44:365-78. [PubMed: 15473973]

Duhamel JR, Colby CL, Goldberg ME. The updating of the representation of visual space in parietal cortex by intended eye movements. Science. 1992; 255:90-92. [PubMed: 1553535]

Fanini A, Assad JA. Direction selectivity of neurons in the macaque lateral intraparietal area. J Neurophysiol. 2009; 101:289-305. [PubMed: 18987126] 
Fecteau JH, Munoz DP. Salience, relevance, and firing: a priority map for target selection. Trends Cogn Sci. 2006; 10:382-90. [PubMed: 16843702]

Freedman DJ, Assad JA. Experience-dependent representation of visual categories in parietal cortex. Nature. 2006; 443:85-88. [PubMed: 16936716]

Freedman DJ, Assad JA. Distinct encoding of spatial and nonspatial visual information in parietal cortex. J Neurosci. 2009; 29:5671-80. [PubMed: 19403833]

Ganguli S, Bisley JW, Roitman JD, Shadlen MN, Goldberg ME, Miller KD. One-dimensional dynamics of attention and decision making in LIP. Neuron. 2008; 58:15-25. [PubMed: 18400159]

Gnadt JW, Andersen RA. Memory related motor planning activity in posterior parietal cortex of macaque. Exp Brain Res. 1988; 70:216-20. [PubMed: 3402565]

Gold JI, Shadlen MN. The neural basis of decision making. Annu Rev Neurosci. 2007; 30:535-74. [PubMed: 17600525]

Goldberg ME, Wurtz RH. Activity of superior colliculus in behaving monkey. II. Effect of attention on neuronal responses. J Neurophysiol. 1972; 35:560-74. [PubMed: 4624740]

Gottlieb J, Goldberg ME. Activity of neurons in the lateral intraparietal area of the monkey during an antisaccade task. Nat Neurosci. 1999; 2:906-12. [PubMed: 10491612]

Gottlieb JP, Kusunoki M, Goldberg ME. The representation of visual salience in monkey parietal cortex. Nature. 1998; 391:481-84. [PubMed: 9461214]

Hallett PE, Adams BD. The predictability of saccadic latency in a novel voluntary oculomotor task. Vision Res. 1980; 20:329-39. [PubMed: 7414965]

Husain M, Nachev P. Space and the parietal cortex. Trends Cogn Sci. 2007; 11:30-36. [PubMed: 17134935]

Ipata AE, Gee AL, Bisley JW, Goldberg ME. Neurons in the lateral intraparietal area create a priority map by the combination of disparate signals. Exp Brain Res. 2009; 192:479-88. [PubMed: 18762926]

Ipata AE, Gee AL, Goldberg ME, Bisley JW. Activity in the lateral intraparietal area predicts the goal and latency of saccades in a free-viewing visual search task. J Neurosci. 2006a; 26:3656-61. [PubMed: 16597719]

Ipata AE, Gee AL, Gottlieb J, Bisley JW, Goldberg ME. LIP responses to a popout stimulus are reduced if it is overtly ignored. Nat Neurosci. 2006b; 9:1071-76. [PubMed: 16819520]

Itti L, Koch C. A saliency-based search mechanism for overt and covert shifts of visual attention. Vision Res. 2000; 40:1489-506. [PubMed: 10788654]

James, W. The Principles of Psychology. New York: Holt; 1890.

Janssen P, Shadlen MN. A representation of the hazard rate of elapsed time in macaque area LIP. Nat Neurosci. 2005; 8:234-41. [PubMed: 15657597]

Johnson PB, Ferraina S, Bianchi L, Caminiti R. Cortical networks for visual reaching: physiological and anatomical organization of frontal and parietal lobe arm regions. Cereb Cortex. 1996; 6:10219. [PubMed: 8670643]

Kiani R, Shadlen MN. Representation of confidence associated with a decision by neurons in the parietal cortex. Science. 2009; 324:759-64. [PubMed: 19423820]

Klein JT, Deaner RO, Platt ML. Neural correlates of social target value in macaque parietal cortex. Curr Biol. 2008; 18:419-24. [PubMed: 18356054]

Klein RM. Inhibition of return. Trends Cogn Sci. 2000; 4:138-47. [PubMed: 10740278]

Koch C, Ullman S. Shifts in selective visual attention: towards the underlying neural circuitry. Hum Neurobiol. 1985; 4:219-27. [PubMed: 3836989]

Kusunoki M, Goldberg ME. The time course of perisaccadic receptive field shifts in the lateral intraparietal area of the monkey. J Neurophysiol. 2003; 89:1519-27. [PubMed: 12612015]

Kusunoki M, Gottlieb J, Goldberg ME. The lateral intraparietal area as a salience map: the representation of abrupt onset, stimulus motion, and task relevance. Vision Res. 2000; 40:145968. [PubMed: 10788652]

Leon MI, Shadlen MN. Representation of time by neurons in the posterior parietal cortex of the macaque. Neuron. 2003; 38:317-27. [PubMed: 12718864] 
Lewis JW, Van Essen DC. Corticocortical connections of visual, sensorimotor, and multimodal processing areas in the parietal lobe of the macaque monkey. J Comp Neurol. 2000; 428:112-37. [PubMed: 11058227]

Li Z. A saliency map in primary visual cortex. Trends Cogn Sci. 2002; 6:9-16. [PubMed: 11849610]

Lynch JC, Mountcastle VB, Talbot WH, Yin TC. Parietal lobe mechanisms for directed visual attention. J Neurophysiol. 1977; 40:362-89. [PubMed: 403251]

Maimon G, Assad JA. A cognitive signal for the proactive timing of action in macaque LIP. Nat Neurosci. 2006; 9:948-55. [PubMed: 16751764]

Mannan SK, Mort DJ, Hodgson TL, Driver J, Kennard C, Husain M. Revisiting previously searched locations in visual neglect: role of right parietal and frontal lesions in misjudging old locations as new. J Cogn Neurosci. 2005; 17:340-54. [PubMed: 15811244]

Maunsell JH. Neuronal representations of cognitive state: reward or attention? Trends Cogn Sci. 2004; 8:261-65. [PubMed: 15165551]

Mazer JA, Gallant JL. Goal-related activity in V4 during free viewing visual search. Evidence for a ventral stream visual salience map. Neuron. 2003; 40:1241-50. [PubMed: 14687556]

Mazzoni P, Bracewell RM, Barash S, Andersen RA. Motor intention activity in the macaque's lateral intraparietal area. I. Dissociation of motor plan from sensory memory. J Neurophysiol. 1996; 76:1439-56. [PubMed: 8890265]

Mirpour K, Arcizet F, Ong WG, Bisley JW. Been there, seen that: a neural mechanism for performing efficient visual search. J Neurophysiol. 2009; 102:3481-91. [PubMed: 19812286]

Moran J, Desimone R. Selective attention gates visual processing in the extrastriate cortex. Science. 1985; 229:782-84. [PubMed: 4023713]

Mountcastle VB, Lynch JC, Georgopoulos A, Sakata H, Acuna C. Posterior parietal association cortex of the monkey: command functions for operations within extrapersonal space. J Neurophysiol. 1975; 38:871-908. [PubMed: 808592]

Ogawa T, Komatsu H. Condition-dependent and condition-independent target selection in the macaque posterior parietal cortex. J Neurophysiol. 2009; 101:721-36. [PubMed: 19073809]

Oristaglio J, Schneider DM, Balan PF, Gottlieb J. Integration of visuospatial and effector information during symbolically cued limb movements in monkey lateral intraparietal area. J Neurosci. 2006; 26:8310-19. [PubMed: 16899726]

Platt ML, Glimcher PW. Neural correlates of decision variables in parietal cortex. Nature. 1999; 400:233-38. [PubMed: 10421364]

Quian Quiroga R, Snyder LH, Batista AP, Cui H, Andersen RA. Movement intention is better predicted than attention in the posterior parietal cortex. J Neurosci. 2006; 26:3615-20. [PubMed: 16571770]

Robinson DA. Eye movements evoked by collicular stimulation in the alert monkey. Vision Res. 1972; 12:1795-808. [PubMed: 4627952]

Robinson DA, Fuchs AF. Eye movements evoked by stimulation of frontal eye fields. J Neurophysiol. 1969; 32:637-48. [PubMed: 4980022]

Robinson DL, Goldberg ME, Stanton GB. Parietal association cortex in the primate: sensory mechanisms and behavioral modulations. J Neurophysiol. 1978; 41:910-32. [PubMed: 98614]

Roitman JD, Brannon EM, Platt ML. Monotonic coding of numerosity in macaque lateral intraparietal area. PLoS Biol. 2007; 5:e208. [PubMed: 17676978]

Roitman JD, Shadlen MN. Response of neurons in the lateral intraparietal area during a combined visual discrimination reaction time task. J Neurosci. 2002; 22:9475-89. [PubMed: 12417672]

Sakata H, Taira M, Murata A, Mine S. Neural mechanisms of visual guidance of hand action in the parietal cortex of the monkey. Cereb Cortex. 1995; 5:429-38. [PubMed: 8547789]

Schiller PH, Stryker M. Single-unit recording and stimulation in superior colliculus of the alert rhesus monkey. J Neurophysiol. 1972; 35:915-24. [PubMed: 4631839]

Seo H, Barraclough DJ, Lee D. Lateral intraparietal cortex and reinforcement learning during a mixedstrategy game. J Neurosci. 2009; 29:7278-89. [PubMed: 19494150]

Serences JT, Yantis S. Selective visual attention and perceptual coherence. Trends Cogn Sci. 2006; 10:38-45. [PubMed: 16318922] 
Sereno AB, Maunsell JH. Shape selectivity in primate lateral intraparietal cortex. Nature. 1998; 395:500-3. [PubMed: 9774105]

Shadlen MN, Newsome WT. Neural basis of a perceptual decision in the parietal cortex (area LIP) of the rhesus monkey. J Neurophysiol. 2001; 86:1916-36. [PubMed: 11600651]

Shibutani H, Sakata H, Hyvarinen J. Saccade and blinking evoked by microstimulation of the posterior parietal association cortex of the monkey. Exp Brain Res. 1984; 55:1-8. [PubMed: 6745342]

Snyder LH, Batista AP, Andersen RA. Coding of intention in the posterior parietal cortex. Nature. 1997; 386:167-70. [PubMed: 9062187]

Snyder LH, Batista AP, Andersen RA. Change in motor plan, without a change in the spatial locus of attention, modulates activity in posterior parietal cortex. J Neurophysiol. 1998; 79:2814-19. [PubMed: 9582248]

Sugrue LP, Corrado GS, Newsome WT. Matching behavior and the representation of value in the parietal cortex. Science. 2004; 304:1782-87. [PubMed: 15205529]

Thier P, Andersen RA. Electrical microstimulation distinguishes distinct saccade-related areas in the posterior parietal cortex. J Neurophysiol. 1998; 80:1713-35. [PubMed: 9772234]

Thomas NW, Pare M. Temporal processing of saccade targets in parietal cortex area LIP during visual search. J Neurophysiol. 2007; 97:942-47. [PubMed: 17079346]

Thompson KG, Hanes DP, Bichot NP, Schall JD. Perceptual and motor processing stages identified in the activity of macaque frontal eye field neurons during visual search. J Neurophysiol. 1996; 76:4040-55. [PubMed: 8985899]

Toth LJ, Assad JA. Dynamic coding of behaviourally relevant stimuli in parietal cortex. Nature. 2002; 415:165-68. [PubMed: 11805833]

Walther D, Koch C. Modeling attention to salient proto-objects. Neural Netw. 2006; 19:1395-407. [PubMed: 17098563]

Wardak C, Olivier E, Duhamel JR. A deficit in covert attention after parietal cortex inactivation in the monkey. Neuron. 2004; 42:501-8. [PubMed: 15134645]

Yang T, Shadlen MN. Probabilistic reasoning by neurons. Nature. 2007; 447:1075-80. [PubMed: 17546027]

Yantis S, Jonides J. Abrupt visual onsets and selective attention: evidence from visual search. J Exp Psychol Hum Percept Perform. 1984; 10:601-21. [PubMed: 6238122]

Yin TCT, Mountcastle VB. Visual input to the visuomotor mechanisms of the monkey's parietal lobe. Science. 1977; 197:1381-83. [PubMed: 408924]

Zhang M, Barash S. Neuronal switching of sensorimotor transformations for antisaccades. Nature. 2000; 408:971-75. [PubMed: 11140683] 

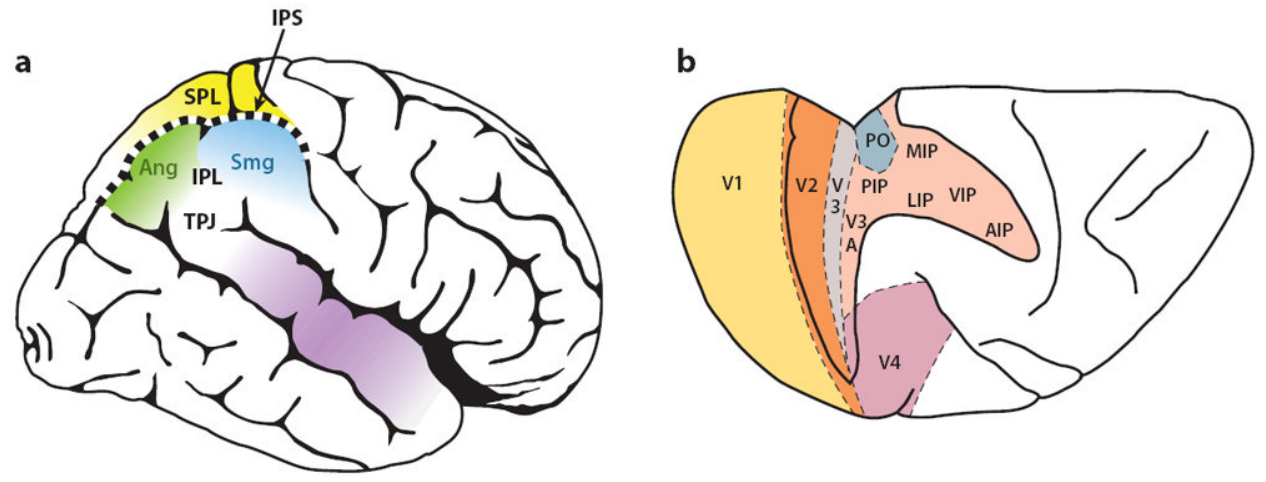

Figure 1.

Posterior parietal cortex of human (left) and macaque monkey (right). (a) The human posterior parietal cortex (PPC) is divided by the intraparietal sulcus (IPS) into the superior parietal lobe (SPL) and the inferior parietal lobe (IPL). The IPL consists of the angular gyrus (Ang) and supramarginal gyrus (Smg) and borders the superior temporal gyrus (purple) at a region often referred to as the temporoparietal junction (TPJ). (b) The lunate and intraparietal sulci are opened up to show the locations of several extrastriate areas in addition to the visually responsive areas within the intraparietal sulcus. These include the parieto-occipital area (PO), the posterior intraparietal area (PIP), the medial intraparietal area (MIP), the lateral intraparietal area (LIP), the ventral intraparietal area (VIP), and the anterior intraparietal area (AIP). Adapted from Husain \& Nachev (2007) and Colby et al. (1988). 
a

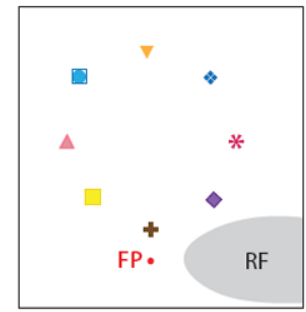

Fixate so all symbols are outside RF

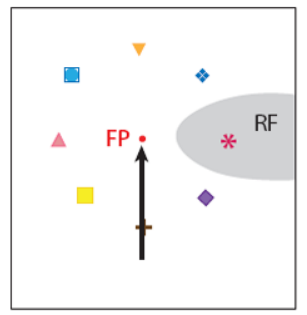

Saccade brings stable stimulus into RF
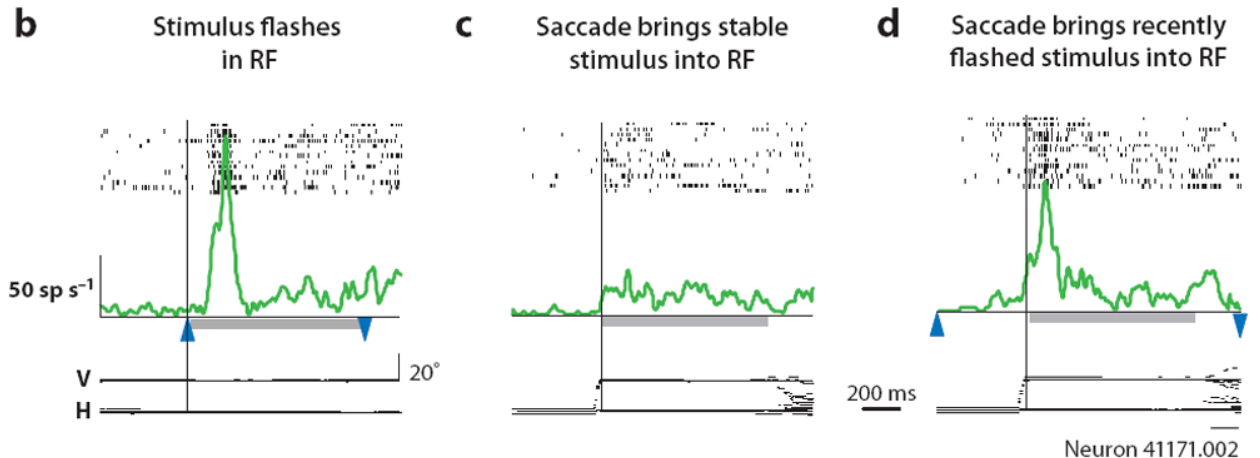

Figure 2.

Effect of a recent flash on the response of an LIP neuron in the stable array task. (a) In this task the eight objects remained on the screen for the duration of the experiment. The monkey initiated the trial by fixating a small spot (FP) positioned such that none of the stable objects appeared in the receptive field (RF). After a short delay the fixation point jumped to the center of the array, bringing one of the objects into the receptive field. (b) The response to a single stimulus flashing in the receptive field during a fixation task. No other stimuli were present on the screen. Activity is aligned on the stimulus onset. (c) The response to the same stimulus, as part of the stable array, moving into the receptive field by a saccade. Activity is aligned by the end of the saccade. (d) A saccade brings a recently flashed stimulus into the receptive field. The stimulus appears approximately $500 \mathrm{~ms}$ before the saccade, and the data are aligned by the end of the saccade. The gray bars beneath the spike density functions show when, during the trial, the stimulus was in the receptive field of the neuron. The up arrows represent the onset of a flashed stimulus, and the down arrows represent its disappearance. Activity is aligned on the saccade end. Adapted from Kusunoki et al. (2000). 

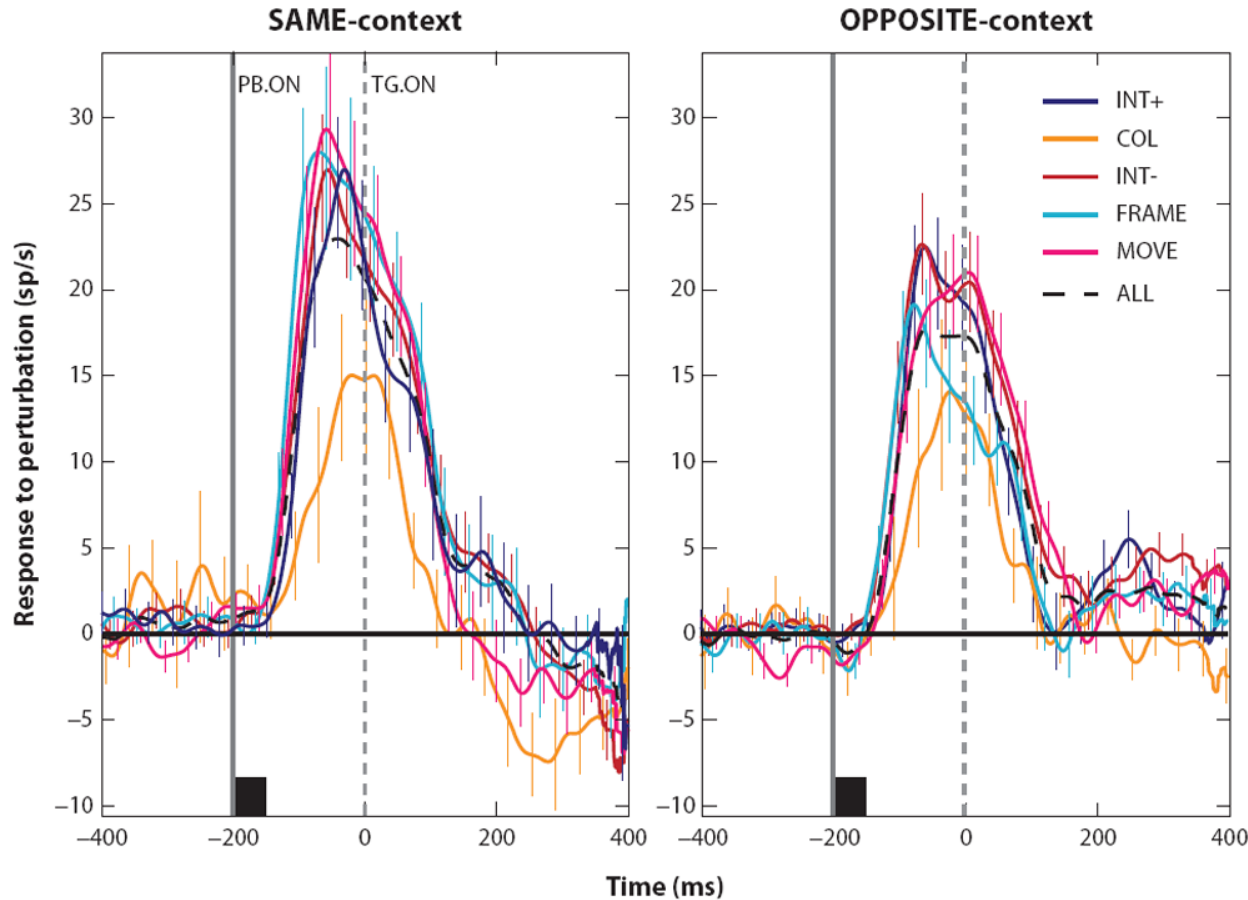

Figure 3.

Responses of a population of LIP neurons to salient events (perturbations) that occurred 200 $\mathrm{ms}$ before stimuli were revealed in a covert visual search task. Data show the responses to perturbations as the difference between responses on trials with and without the perturbation occurring on trials in which the animal knew that the target would appear on the SAME or OPPOSITE location as the perturbation. The perturbations were: an increase in luminance (INT+); a change in color (COL); a decrease in luminance (INT-); the appearance of frame surrounding one pattern (FRAME); and a back-and-forth radial movement (MOVE).

Perturbation onset (PB.ON) is indicated by the solid vertical line; and search target onset (TG.ON) is indicated by the dashed vertical line. Reproduced from Balan \& Gottlieb (2006) with permission. 
a
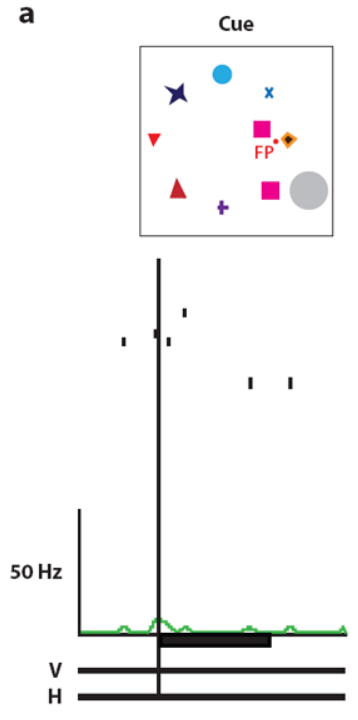

b
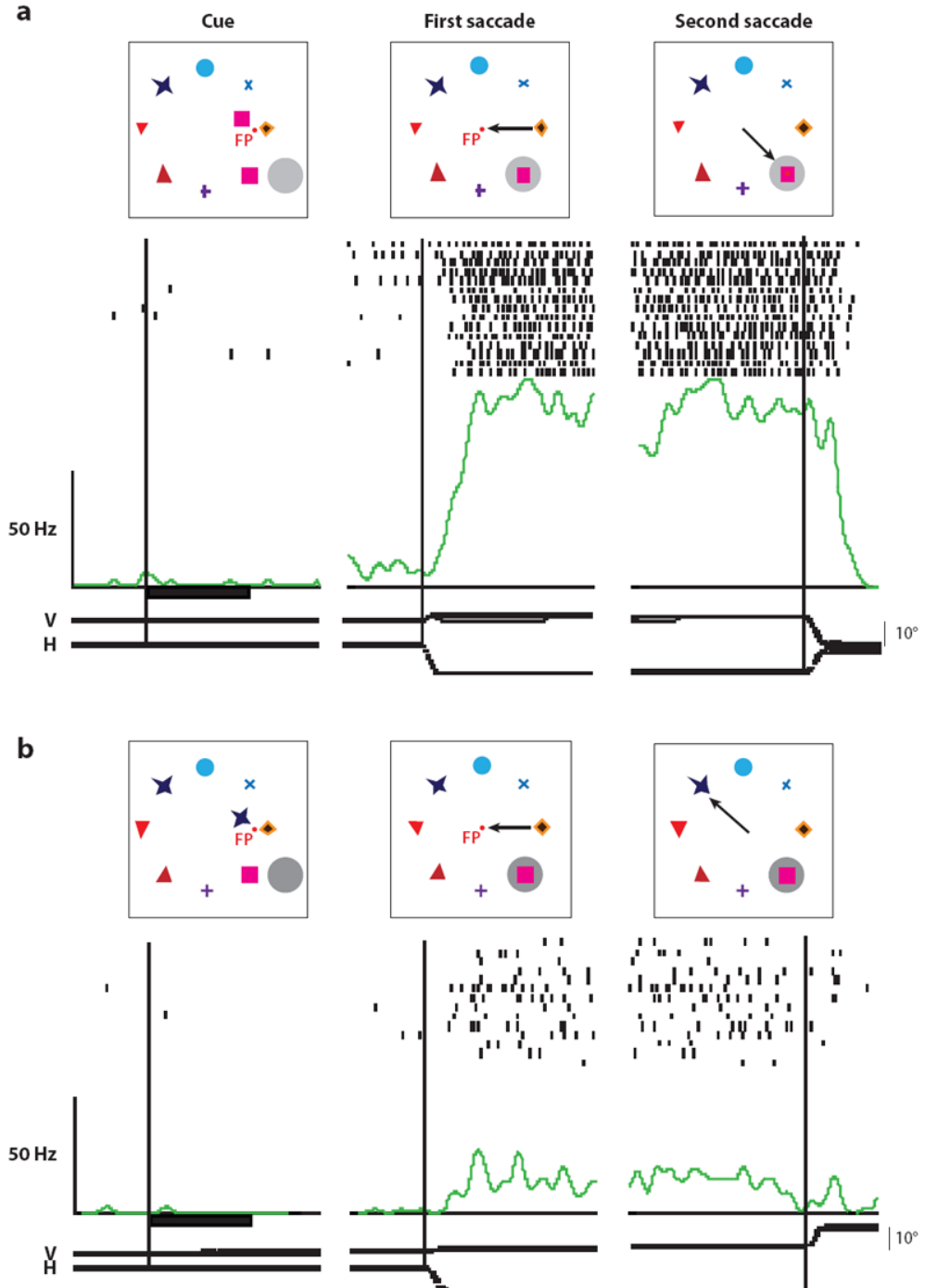
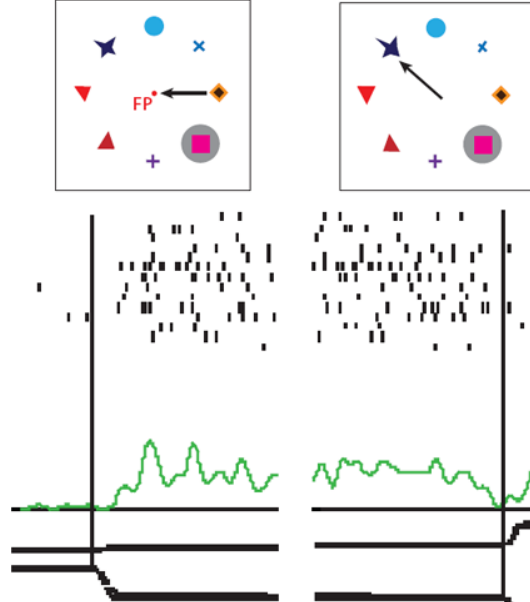

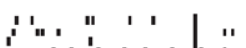

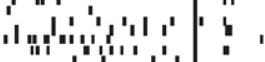
إ.

Figure 4.

Response of an LIP neuron in a stable array task requiring a saccade to a cued object. While the monkey was fixating outside of the array, a cue was flashed. The fixation point (FP) then jumped into the center of the array bringing an object into the receptive field. The animal then waited until the fixation point was extinguished and made a saccade to the cued object. (a) The cued object was within the receptive field after the first saccade; $(b)$ the same object, this time not the target of the saccade, was brought into the receptive field by the first saccade. Each trio of raster plots shows the response of the neuron in the same trials synchronized on the cue (left), first saccade beginning (middle) and second saccade beginning (right). Adapted from Kusunoki et al. (2000) with permission. 

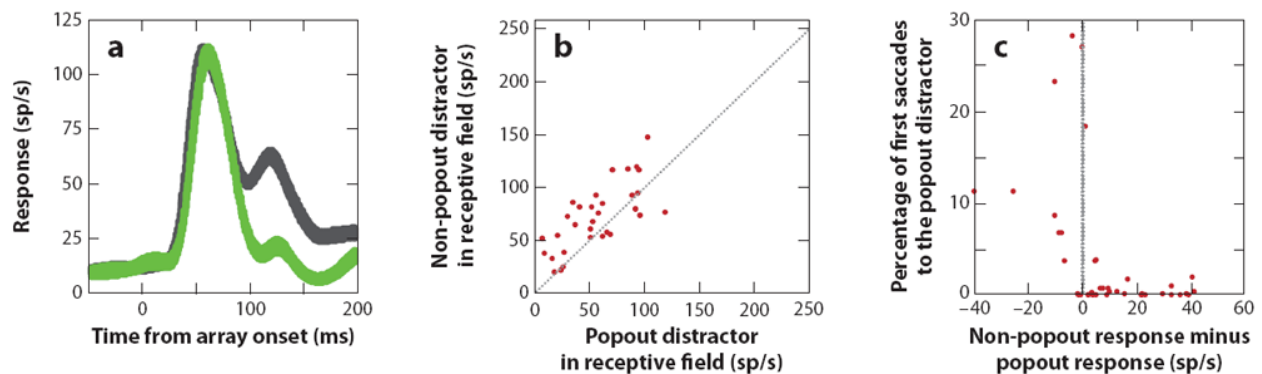

Figure 5.

LIP responses to a task-irrelevant popout distractor. (a) Responses of a single neuron to the appearance of an array object in the receptive field are plotted against time from target onset. Gray trace: response to a non-popout distractor in the receptive field when the monkey made a saccade to the target elsewhere. Green trace: response to the popout distractor in the receptive field when the monkey made a saccade to the target elsewhere. $(b)$ The response of each cell from a 50-ms epoch, starting $40 \mathrm{~ms}$ after the latency, to the nonpopout distractor is plotted against the response of the same cell to the popout distractor. (c) Cell by cell correlation of response difference with saccade suppression. The percentage of trials in which the first saccade went to the popout distractor for each cell is plotted against the difference in the number of spikes between the responses (80-130 ms) to the non-popout and popout distractors for the cell recorded in that session. Reproduced from Ipata et al. (2006b) with permission. 
a
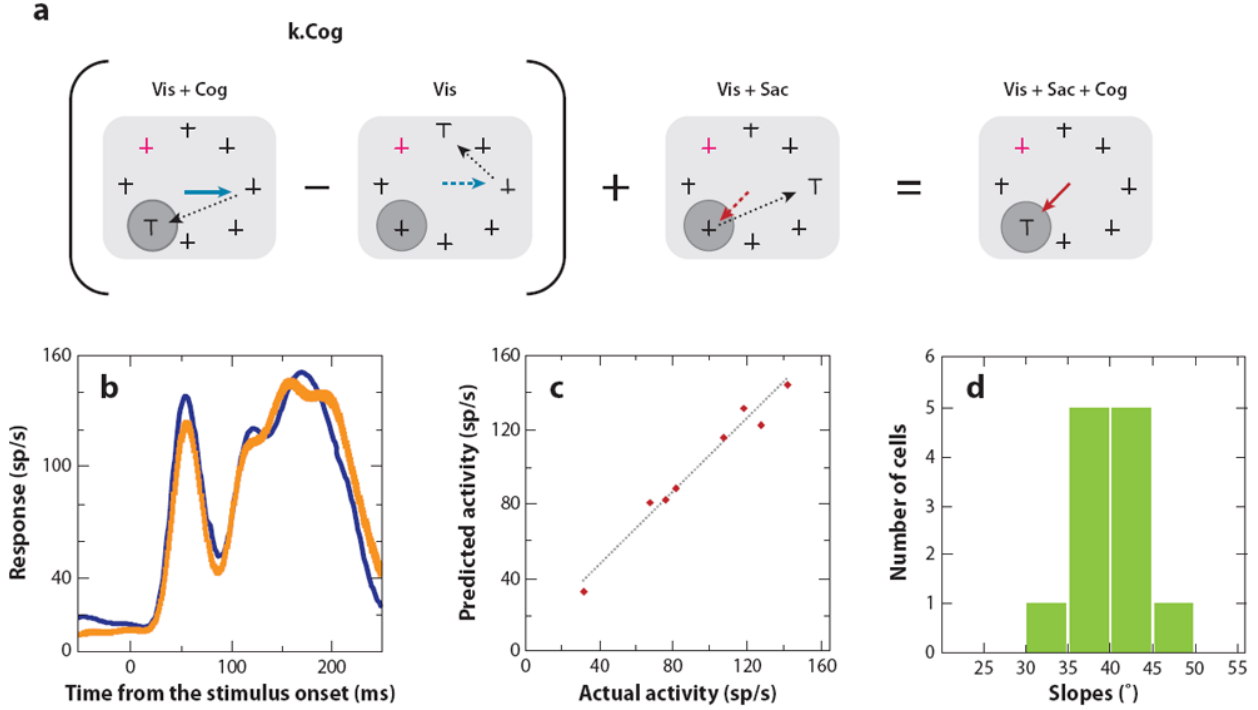

Figure 6.

Summation in LIP. (a) A cartoon illustration of the test of summation. The cognitive signal (Cog) was in trials in which the target was in the receptive field. $\mathrm{k}$ is the constant that accounts for the different strength of the cognitive signal (see text for more details). The visual signal (Vis) was in all trials in which a stimulus appeared in the receptive field. The saccadic signal (Sac) was in trials in which the monkey made a saccade toward the receptive field. (b) Single cell responses from trials in which the saccade was made to the target inside the receptive field (orange trace) are compared to the calculated signal obtained by summing the three components obtained in different trial types (blue trace). (c) The mean activity in 20-ms time intervals from $80 \mathrm{~ms}$ to $240 \mathrm{~ms}$ after array onset measured in saccade-to-targetin-the-receptive-field trials (abscissa) against the activity in the same intervals calculated from the other three trial types (ordinate) for the same single neuron. Least-squares correlation line is shown with a dashed gray line. (d) Bar plot of the distribution of the slopes, in degrees, from the regression analyses for each cell. Adapted from Ipata et al. (2009) with permission. 
a

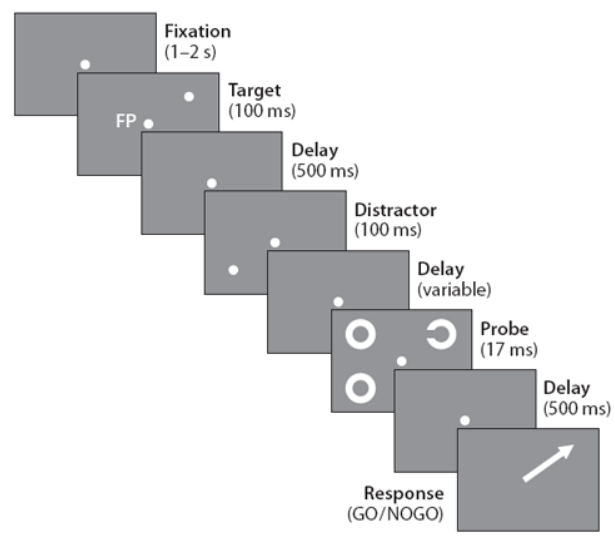

b
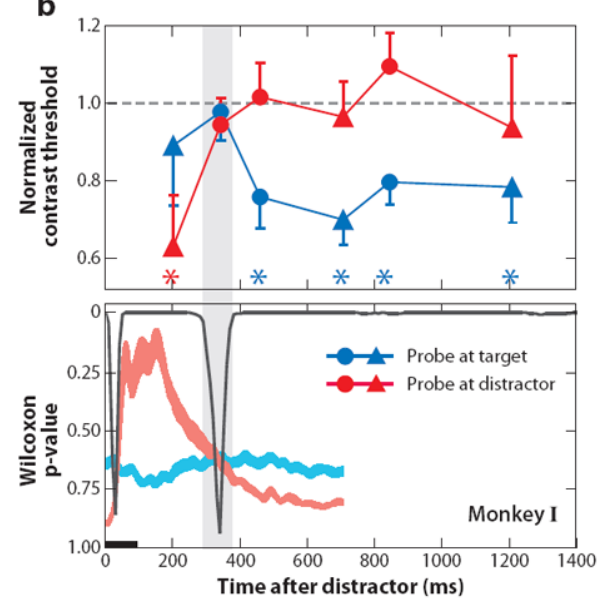

Figure 7.

The task and data collected to compare the locus of attention with activity in LIP. (a) The task was based on a memory-guided saccade task, with a task-irrelevant distractor. In this task, before the fixation point (FP) was extinguished four rings appeared. One of the rings had a gap on either the left or the right (the probe). The monkey had to identify the side of ring that the gap was on and indicate it either by making the planned memory-guided saccade when the fixation point was extinguished (GO) or by canceling the saccade and maintaining fixation until the end of the trial (NOGO). (b) Pooled behavioral and physiological data from a single animal. The thin traces in the top panel show the animal's behavioral performance plotted as normalized threshold. Points that are significantly beneath the black dashed line indicate an attentional advantage $(*)$. The thick traces in the lower panel show the mean spike density functions from a population of 23 neurons (the width of the trace shows the SEM). Blue traces show data from trials in which the probe was placed at the target site, and the distractor had flashed elsewhere. Red traces show data from trials in which the probe was placed at the distractor site and the target had flashed elsewhere. The thin gray trace shows the result of a running statistical test showing when the thick red and blue traces were indistinguishable (gray block). The black bar shows the onset and duration of the distractor. From Bisley \& Goldberg (2003) as modified in Bisley \& Goldberg (2006) with permission. 


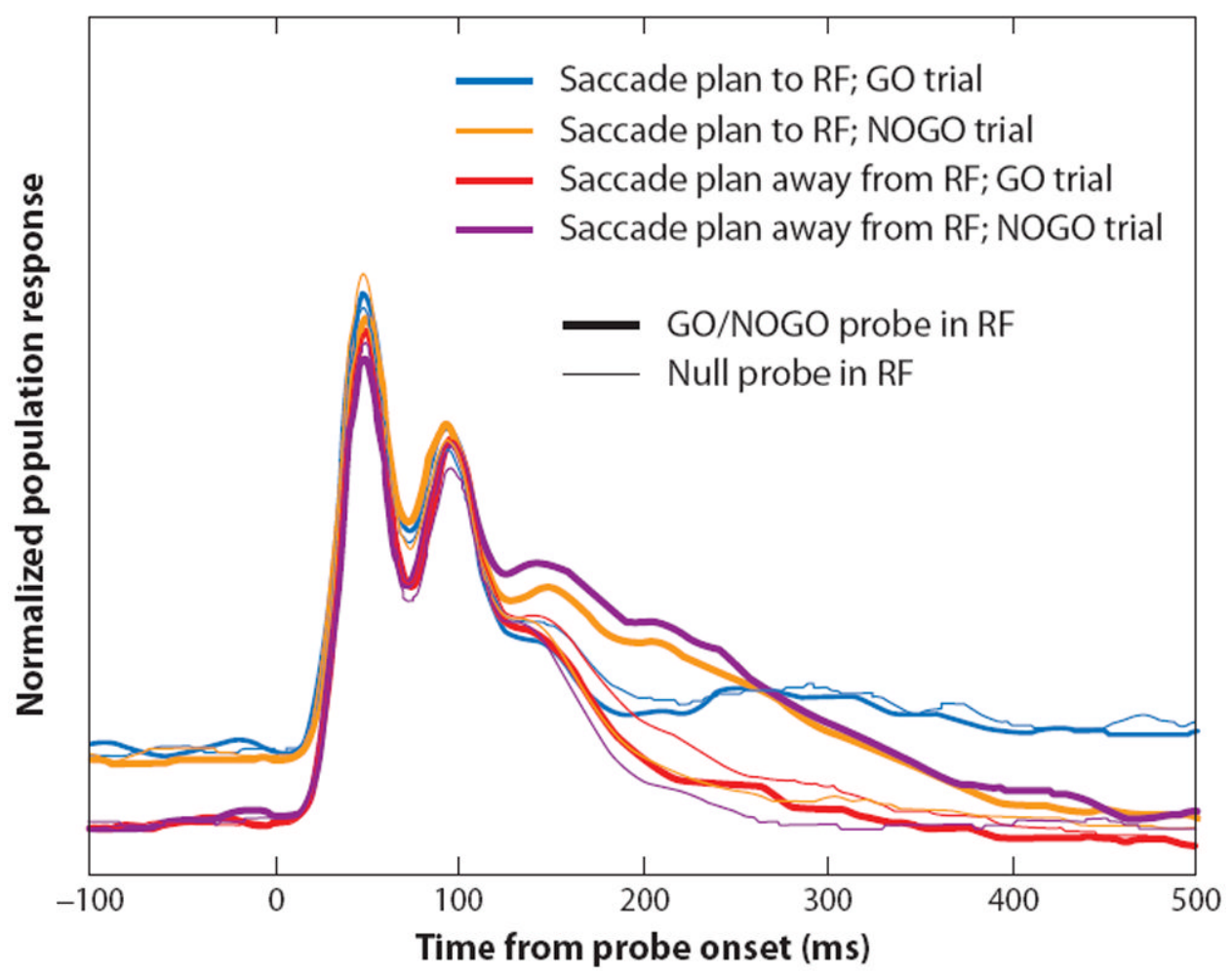

Figure 8.

The normalized population responses from one monkey to the GO, NOGO and null probes in the contrast sensitivity task (Figure 7a). The color coding indicates the direction of saccade plan and whether the trial was a GO or NOGO trial, and the thickness of the line indicates whether a GO, NOGO, or null probe was in the receptive field. Adapted from Bisley \& Goldberg (2006) with permission. 
a

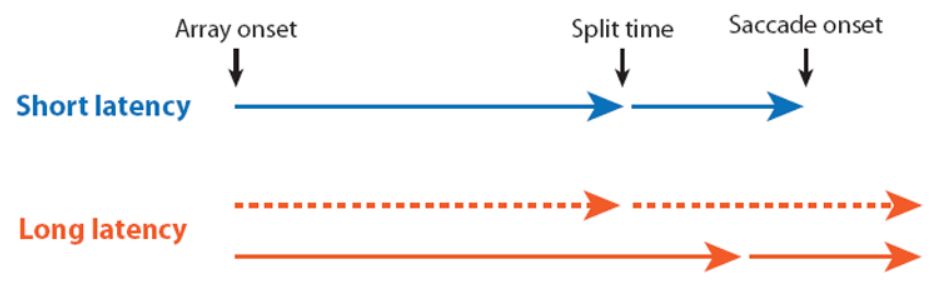

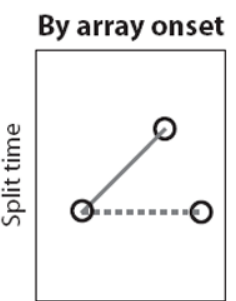

Latency

b

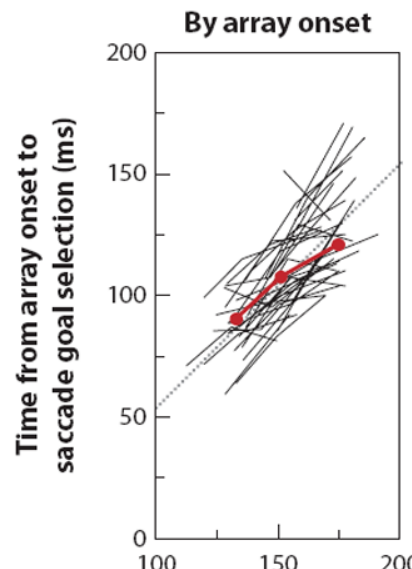

By saccade onset

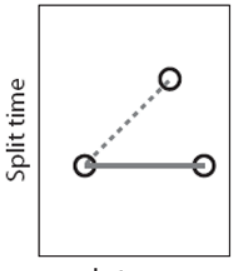

Latency
C

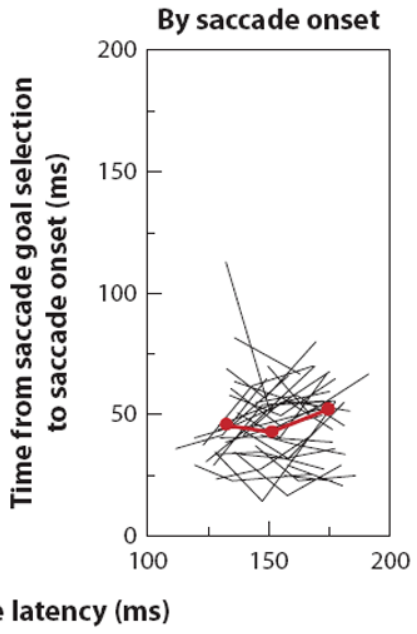

Figure 9.

Relationship between LIP activity and first saccadic latency. (a) An example of a short latency trial is compared to two possible long latency trials showing the two extreme possibilities in how the extra time is added to latency. In the upper (dashed) example, the time from array onset until the split time is identical, so all the variability in latency time comes in to the process later than LIP. This would suggest LIP is not involved in saccadic selection. In the lower (solid) example, the extra latency time comes before the split time in LIP. This would suggest that LIP is driving the saccade. The two sets of hypothesized results (dashed and solid) are plotted in the small panels comparing the split time calculated by array onset and split time calculated by saccade onset. (b) The time from array onset to split time is plotted against the mean first saccadic latency for each group for each cell. The dotted line shows an example slope of 1. (c) The time from the split time to saccade onset is plotted against the mean first saccadic latency for each group for each cell. The flat lines suggest that a saccade is generated a set time after a peak is identified in LIP. For $(b)$ and (c), the black lines connect points from the same cell and the solid red lines connect the population means. Adapted from Ipata et al. (2006a) with permission. 